\title{
BIR Domain
}

National Cancer Institute

\section{Source}

National Cancer Institute. BIR Domain. NCI Thesaurus. Code C13906.

Containing perfectly conserved histidine and cysteines residues. the BIR domain is about 70 residues long arranged in tandem repeats separated by a linker of variable length. Found in IAP (Inhibitor of Apoptosis Protein) Family proteins, it seems to confer cell death-preventing activity. Except NAIP, family members typically contain two or three BIR repeats and a C-terminal RING finger. A second group of BIR-domain-containing proteins (BIRPs) include mammalian Bruce and Survivin proteins, as well as BIR-

containing proteins in yeasts and C. eleg ans. Survivin-like BIRPs regulate cytokinesis and mitotic spindle formation. $(\mathrm{NCl})$ 